\title{
A Case of Extrusion of a Solid Silicone Tire Migrating through the Superior Rectus Muscle with Aeromonas hydrophila Infection following a Scleral Buckling Procedure
}

\author{
Shinji Makino and Yukihiro Sato \\ Department of Ophthalmology, Jichi Medical University, 3311-1 Yakushiji, Tochigi, Shimotsuke 329-0498, Japan \\ Correspondence should be addressed to Shinji Makino, makichan@jichi.ac.jp \\ Received 12 October 2012; Accepted 31 October 2012 \\ Academic Editors: H. Atilla, H. Y. Chen, and E. Chihara
}

Copyright (C) 2012 S. Makino and Y. Sato. This is an open access article distributed under the Creative Commons Attribution License, which permits unrestricted use, distribution, and reproduction in any medium, provided the original work is properly cited.

To our knowledge, there are no reports of Aeromonas hydrophila infection after a scleral buckling procedure. Also, migration of a silicone explant element through the rectus muscles is extremely rare. Herein, we describe a case experiencing extrusion of a solid silicone tire migrating through the superior rectus muscle with Aeromonas hydrophila infection following a scleral buckling procedure. A 42-year-old man was referred to our hospital complaining of ocular pain and purulent discharge in his left eye which has persisted for several months. He had a history of bilateral rhegmatogenous retinal detachment which had been treated with scleral buckling. The left eye showed extrusion of the solid silicone buckle which had migrated through the superior rectus muscle and an infection in the upper quadrant of the sclera. The buckle was removed, and the patient was treated with antibiotics. After the removal of the buckle, the symptoms showed rapid amelioration and there was no recurrence of retinal detachment. Aeromonas hydrophila was isolated from the discharge and the removed explant. He used well water in daily life. In this case, the Aeromonas hydrophila infection of the extruded buckle might have originated from contaminated well water.

\section{Introduction}

The Aeromonas genus consists of Gram-negative bacilli, found throughout the environment, particularly in water and soil. Only the three phenospecies, Aeromonas hydrophila, Aeromonas sorbia, and Aeromonas caviae, are of clinical significance in humans [1]. Aeromonas hydrophila infections usually occur under specific circumstances, such as in immunocompromised patients, especially those with malignancy or liver diseases. Aeromonas hydrophila has been reported to cause conjunctivitis [2], corneal ulcer [3, 4], contact lens-related keratitis [5], orbital cellulitis [6], and endophthalmitis [7-12]. To our knowledge, there are no reports of Aeromonas hydrophila infection after a scleral buckling procedure.

Extrusion and infection of the buckle are infrequent complications of scleral buckling procedures [13-18]. However, there are a few reported cases describing migration of a silicone explant element through the rectus muscles [19-21].
We present a case with extrusion of a solid silicone tire migrating through the superior rectus muscle with Aeromonas hydrophila infection following a scleral buckling procedure.

\section{Case Report}

A 42-year-old man presented with ocular pain, hyperemic swollen conjunctiva, and purulent discharge in his left eye which lasted for several months prior to his first visit to our facility. His ocular history was significant for bilateral rhegmatogenous retinal detachment 16 years prior to the current presentation. The right eye had been successfully treated with a scleral buckling procedure and vitrectomy 9 years earlier. The left eye underwent a scleral buckling procedure with placement of a $270^{\circ}$-solid silicone explant (MIRA number 277) with a $360^{\circ}$-encircling band (MIRA number 240). Upon examination on presentation, visual acuity was 20/20 in the right eye and 20/200 in the left eye. 


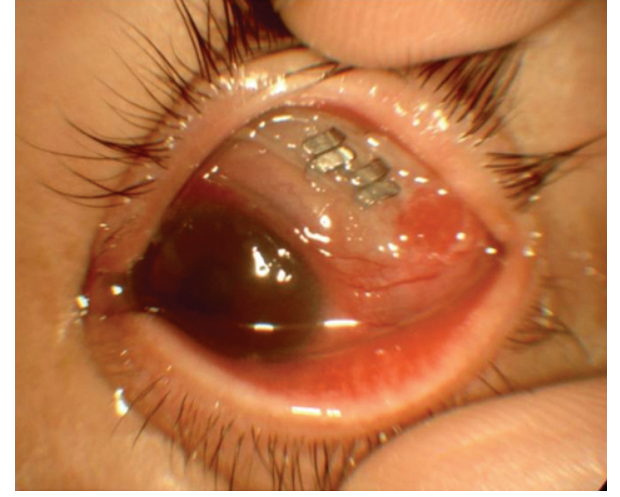

Figure 1: Photograph of the left eye at the time of presentation. An extrusion of the buckle which had migrated through the superior rectus muscle and infected sclera was observed through the conjunctival fistula.

The anterior segment of the right eye showed postoperative aphakia, and ophthalmoscopy revealed an attached retina with indentation of the scleral buckle at $360^{\circ}$. The left eye demonstrated hyperemic and chemotic conjunctiva and extensive yellowish discharge. Conjunctival fistula was present in the upper quadrants. An extrusion of the buckle had migrated through the superior rectus muscle and scleral infection was observed through the conjunctival fistula (Figure 1). An encircling band and a solid explant were removed (Figure 2), and the patient was treated with topical and systemic broad spectrum antibiotics. After the removal of the buckle, the symptoms improved rapidly and there was no recurrence of retinal detachment. His visual acuity improved to 60/200. Aeromonas hydrophila was isolated from the discharge and the removed explant. He used well water in daily life. Aeromonas hydrophila was not, however, isolated from the well water.

\section{Discussion}

To our knowledge, this is the first case report describing late infection caused by Aeromonas hydrophila following a scleral buckling procedure.

Among the infrequent complications associated with scleral buckling procedures are inflammation, infection, extrusion, and intrusion [13-18]. Postoperative extrusion or infection with exposure of the scleral buckling material is reportedly more common with the use of silicone sponge explants $(2.7 \%-18.0 \%)$ than with that of hard silicone explants $(0.2 \%-1.4 \%)$ [14].

These complications also are more common in patients with explants than in those with implants. However, a few cases with extrusion and anterior displacement of a buckle migrating through the rectus muscles have been reported [19-21]. In our case, it was thought that the buckle had migrated though the superior rectus muscle. We speculated that anterior displacement of the buckle had eroded the superior rectus muscle first, followed by readhesion of the superior rectus muscle to the sclera and extrusion of the buckle.

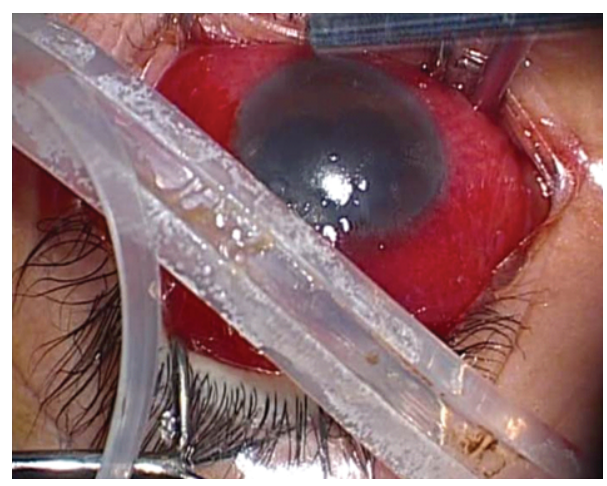

FIGURE 2: Photograph of the removed buckle. Mucopurulent pus is seen around the buckle.

Folk et al. [13] reported the incidence of scleral abscess after buckling procedures to be $0.58 \%$. Of the bacteria identified in scleral buckling infections, coagulase-negative Staphylococcus species are the most common, and in acuteonset scleral explant infection, which is relatively common, Staphylococcus aureus, Staphylococcus epidermidis, Proteus mirabilis, and Pseudomonas aeruginosa are usually identified [13-18]. However, according to our literature search, there have been no reports of Aeromonas hydrophila infection after a scleral buckling procedure. In our present case, Aeromonas hydrophila infecting the extruded buckle might have been derived from well water. Aeromonas species were reportedly isolated from 43 of 157 (27.4\%) well water samples, and 36 of these 43 (83.7\%) were Aeromonas hydrophila [22]. Although these organisms are found throughout the year, isolation ratios were higher in the summer $(44.7 \%)$ than in the winter (17.2\%) months.

Thus, we speculated that undetected Aeromonas hydrophila from the well water used by this patient had caused the infection prior to testing, at a time when bacterial levels in the water would have been higher. Aeromonas hydrophila is highly pathogenic especially to the eye, triggering a robust inflammatory response with a rapid clinical course causing extensive necrosis with suppurative inflammation, and has a poor visual prognosis.

In conclusion, the possibility of an Aeromonas infection should be considered in cases with buckle infections, especially in the presence of environmental factors such wellwater use in daily life.

\section{Conflict of Interests}

The authors have no financial or proprietary interests related to this paper.

\section{References}

[1] J. M. Janda, "Recent advances in the study of the taxonomy, pathogenicity, and infectious syndromes associated with the genus Aeromonas," Clinical Microbiology Reviews, vol. 4, no. 4, pp. 397-410, 1991. 
[2] J. A. Smith, "Ocular Aeromonas hydrophila," American Journal of Ophthalmology, vol. 89, no. 3, pp. 449-451, 1980.

[3] F. T. Feaster, R. M. Nisbet, and J. C. Barber, "Aeromonas hydrophila corneal ulcer," American Journal of Ophthalmology, vol. 85, no. 1, pp. 114-117, 1978.

[4] F. Carta, A. Pinna, S. Zanetti, A. Carta, M. Sotgiu, and G. Fadda, "Corneal ulcer caused by Aeromonas species," American Journal of Ophthalmology, vol. 118, no. 4, pp. 530-531, 1994.

[5] P. R. Sankaridung, N. Vuppala, A. Sreedharan, J. Vadlamudi, and G. N. Rao, "Gram negative bacteria and contact lens induced acute red eye," Indian Journal of Ophthalmology, vol. 44, no. 1, pp. 29-32, 1996.

[6] S. Y. Chou, C. C. Tsai, S. C. Kau, H. C. Kau, and W. M. $\mathrm{Hsu}$, "Aeromonas hydrophila orbital cellulitis in a patient with myelodysplastic syndrome," Journal of the Chinese Medical Association, vol. 67, no. 1, pp. 51-53, 2004.

[7] K. L. Cohen, P. R. Holyk, L. R. McCarthy, and R. L. Peiffer, "Aeromonas hydrophila and Plesiomonas shigelloides endophthalmitis," American Journal of Ophthalmology, vol. 96, no. 3, pp. 403-404, 1983.

[8] J. S. Frieling, R. Rosenberg, M. Edelstein, S. D. Colby, and N. N. Kopelowitz, "Endogenous Aeromonas hydrophila endophthalmitis," Annals of Ophthalmology, vol. 21, no. 3, pp. 117$118,1989$.

[9] T. Tamura and T. Hida, "A case of endogenous Aeromonas hydrophila endophthalmitis," Journal of Japanese Ophthalmological Society, vol. 107, no. 9, pp. 535-537, 2003.

[10] D. Kishi, T. Choshi, C. S. Matsumoto, and H. Yatsuka, "A case of endophthalmitis in which Aeromonas hydrophila was isolated," Folia Ophthalmologica Japonica, vol. 54, no. 6, pp. 466-468, 2003.

[11] M. I. Khan, G. Walters, and T. Metcalfe, "Bilateral endogenous endophthalmitis caused by Aeromonas hydrophila," Eye, vol. 21, no. 9, pp. 1244-1245, 2007.

[12] H. J. Sohn, D. H. Nam, Y. S. Kim, and H. J. Paik, "Endogenous Aeromonas hydrophila endophthalmitis in an immunocompromised patient," Korean Journal of Ophthalmology, vol. 21, no. 1, pp. 45-47, 2007.

[13] J. C. Folk, J. Cutkomp, and F. P. Koontz, "Bacterial scleral abscesses after retinal buckling operations. Pathogenesis, management, and laboratory investigations," Ophthalmology, vol. 94, no. 9, pp. 1148-1154, 1987.

[14] M. Roldan-Pallares, J. L. C. Sanz, S. A. Susi, and M. F. Refojo, "Long-term complications of silicone and hydrogel explants in retinal reattachment surgery," Archives of Ophthalmology, vol. 117, no. 2, pp. 197-201, 1999.

[15] D. Watanabe, J. Fujie, S. Kawano, and N. Kubota, "Four cases of late infection following scleral buckling procedure," Journal of Japanese Ophthalmological Society, vol. 101, no. 6, pp. 520$524,1997$.

[16] Q. D. Nguyen, K. Lashkari, T. Hirose, R. C. Pruett, J. W. McMeel, and C. L. Schepens, "Erosion and intrusion of silicone rubber scleral buckle: presentation and management," Retina, vol. 21, no. 3, pp. 214-220, 2001.

[17] J. F. Le Rouic, O. Bettembourg, F. D'Hermies, F. Azan, G. Renard, and D. Chauvaud, "Late swelling and removal of Miragel buckles: a comparison with silicone indentations," Retina, vol. 23, no. 5, pp. 641-646, 2003.

[18] W. J. Wirostko, D. J. Covert, D. P. Han et al., "Microbiological spectrum of organisms isolated from explanted scleral buckles," Ophthalmic Surgery Lasers and Imaging, vol. 40, no. 2, pp. 201-202, 2009.
[19] I. Ashkenazi, J. Moisseiev, E. Bartov, and G. Treister, "Preserved action of a rectus muscle after transection by an encircling solid silicone band," British Journal of Ophthalmology, vol. 75, no. 8, pp. 508-509, 1991.

[20] A. M. Maguire, M. A. Zarbin, and D. Eliott, "Migration of solid silicone encircling element through four rectus muscles," Ophthalmic Surgery, vol. 24, no. 9, pp. 604-607, 1993.

[21] T. Kinoshita, T. Sakurai, H. Takenaka, T. Mano, and T. Maeno, "A case of extrusion of silicone buckle with erosion of superior rectus muscle following encircling surgery," Japanese Journal of Clinical Ophthalmology, vol. 59, no. 8, pp. 1321-1324, 2005.

[22] T. Okitsu, Y. Asai, T. Yasuda, A. Matsubara, and K. Takizawa, "Detection of Aeromonas species in well-water," Japanese Journal of Public Health, vol. 33, no. 7, pp. 317-321, 1986. 


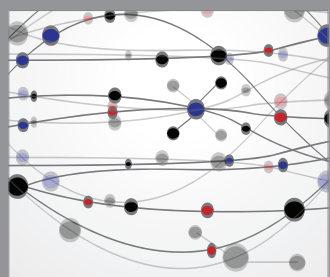

The Scientific World Journal
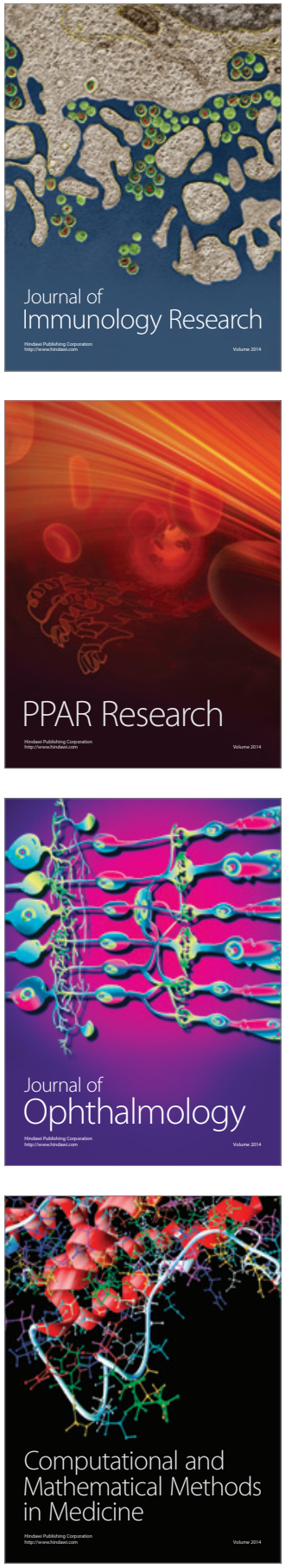

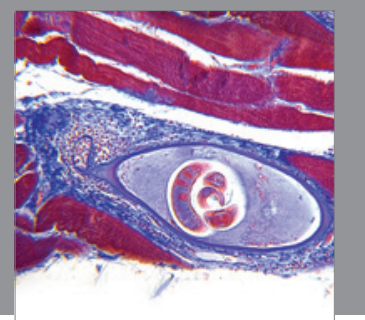

Gastroenterology

Research and Practice
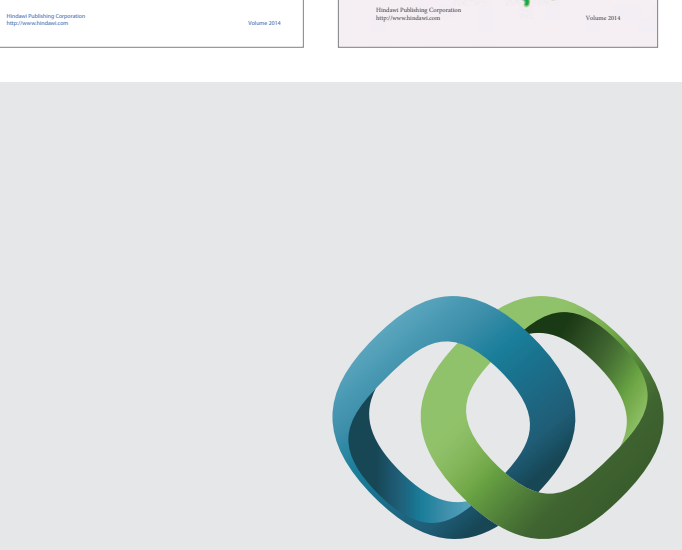

\section{Hindawi}

Submit your manuscripts at

http://www.hindawi.com
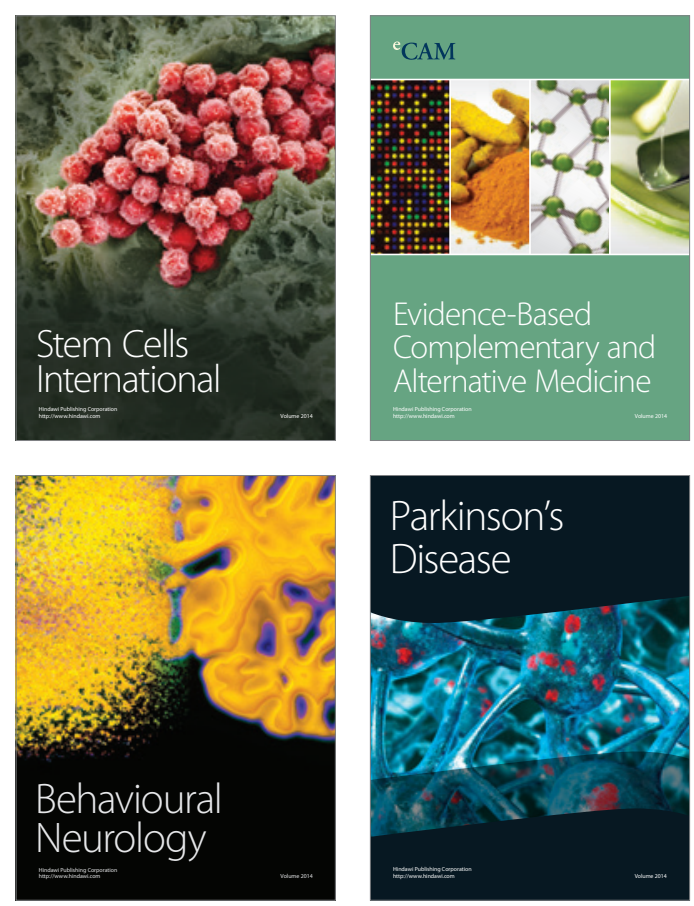

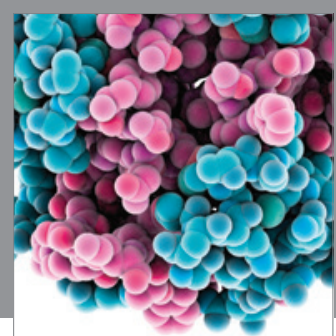

Journal of
Diabetes Research

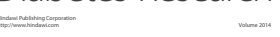

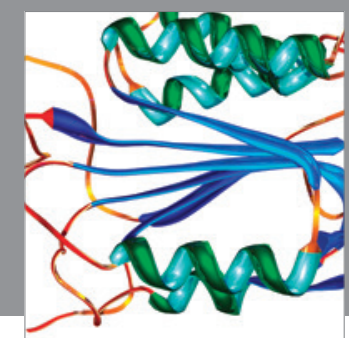

Disease Markers
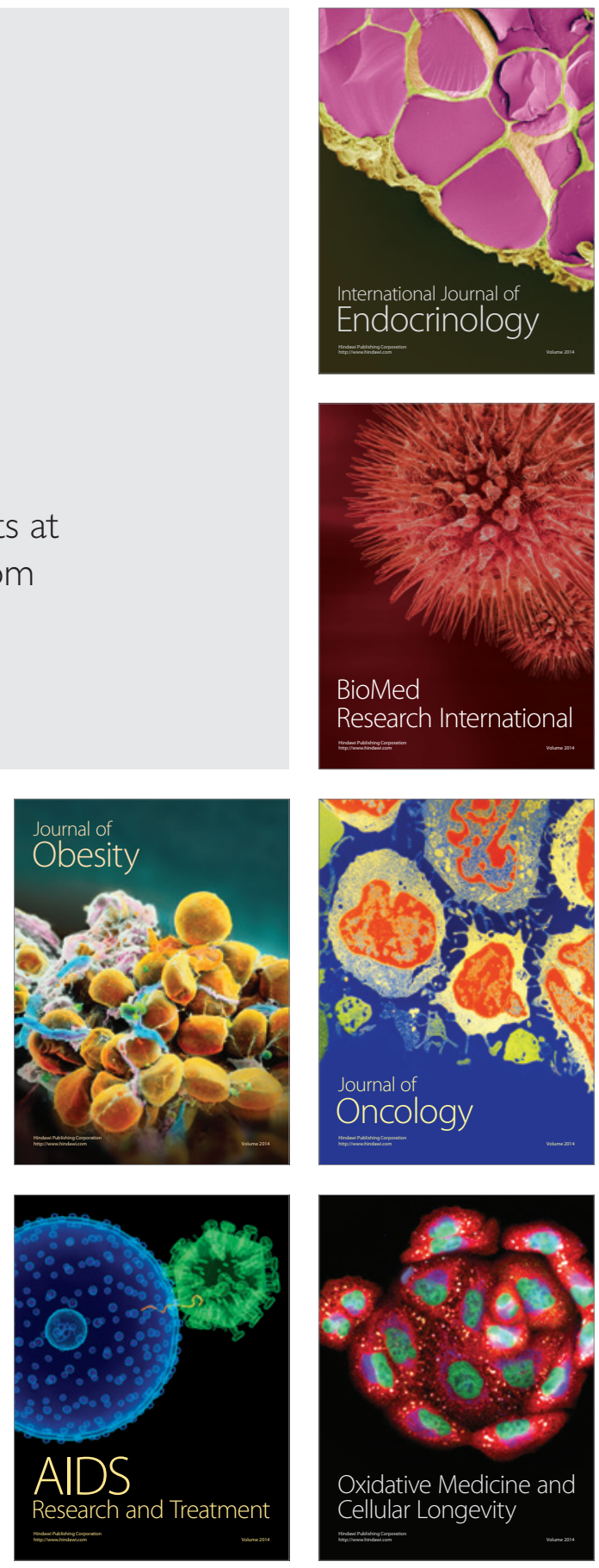